\title{
COMPORTAMENTO DA MISTURA SOLO-EMULSÃO PARA O SISTEMA VIÁRIO DE URUCU (COARI-AM)
}

\author{
Eude de Paula Rebelo ${ }^{1}$ \\ Marcos Raiker Printes Ferreira ${ }^{2}$ \\ Consuelo Alves da Frota ${ }^{3}$
}

\begin{abstract}
Resumo: O trabalho em pauta se ambienta na Província Petrolífera de Urucu, situada no Município de Coari - AM. A descoberta de poços de petróleo pela Petrobrás (Petróleo Brasileiro S.A.) nessa localidade gerou a necessidade de aperfeiçoamento técnico dos pavimentos locais, devido principalmente a não presença do material granular em suas camadas. Neste trabalho estudou-se o efeito da adição da emulsão asfáltica RL-1C a um solo siltoso, característico dessa região, nos teores de $1 \%, 2 \%, 5 \%$ e $8 \%$, com tempo de aeração de 0 e $1 \mathrm{~h}$, e período de cura ao ar livre de 0 e 7 dias. Analisou-se o comportamento mecânico do solo natural e das misturas solo-emulsão pelos ensaios de resistência à compressão simples (RCS) e triaxial de cargas repetidas (MR). Os resultados revelaram especialmente: (a) melhora na deformação pela adição da emulsão, indicada no ensaio de RCS; b) ganho na resistência para $1 \%$ de emulsão, após sete dias de cura, e (c) melhora dos valores do Módulo de Resiliência (MR) em relação ao solo natural, para amostras com 2\% de emulsão, sem aeração e sete dias de cura.
\end{abstract}

Palavras-chave: Mistura solo-emulsão, Região amazônica, Módulo de Resiliência.

Abstract: The present study was developed in the Urucu Oil Province, located in the city of Coari-AM. The discovery of oil wells at this site brought the need to improve local pavements. This need is driven by the low mechanical strength of these pavements, mainly due to the lack of granular material in its layers. In this paper is studied the effect of adding asphalt emulsion RL-1C to a silty soil, which is characteristic of this region, in levels of $1 \%, 2 \%, 5 \%$ and $8 \%$, with aeration time of 0 and $1 \mathrm{~h}$ and outdoor dry curing period of 0 and 7 days. We analyzed the mechanical behavior of natural soil and soil-emulsion mixtures using the unconfined compression test (UCT) and the repeated load triaxial test. The results have revealed the following: (a) an improvement in the deformation by the addition of the emulsion as indicated in UCT test; b) an improvement in resistance for $1 \%$ of emulsion after seven days of curing; (c) the improving of the Resilience Module (RM) values, when compared with the natural soil, for samples with $2 \%$ of emulsion, without aeration and seven days of curing.

Keywords: Soil-Emulsion Mixture, Amazon Region, Resilience Module.

\footnotetext{
${ }^{1}$ Universidade Federal do Amazonas - UFAM. Av General Rodrigo Octávio, 6200, Coroado I. Cep: 69077000. E-mail: eude.paula@ hotmail.com

${ }^{2}$ Universidade Federal do Amazonas - UFAM. Av General Rodrigo Octávio, 6200, Coroado I. Cep: 69077000. E-mail: ferreira_mrp@yahoo.com.br

${ }^{3}$ Universidade Federal do Amazonas - UFAM. Av General Rodrigo Octávio, 6200, Coroado I. Cep: 69077000. E-mail: cafrota@ufam.edu.br
}

ENGEVISTA, V. 16, n. 2, p.180-190, Junho 2014 


\section{INTRODUÇÃO}

O estudo em pauta ambienta-se na Província Petrolífera de Urucu, área de extração de gás e petróleo da Petrobrás S.A., localizada no município de Coari, Estado do Amazonas. Urucu situa-se na

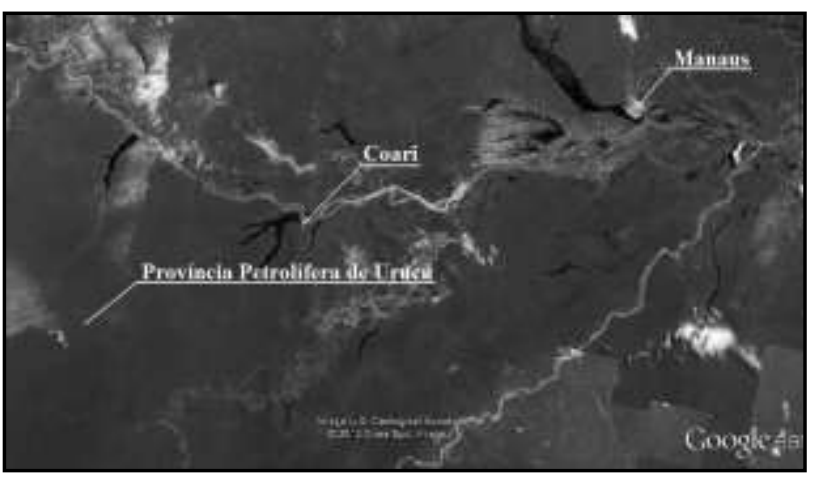

selva amazônica, nas coordenadas $5^{\circ}$ de Latitude Sul e $65^{\circ}$ de Longitude Oeste, a $650 \mathrm{~km}$ de Manaus, sendo denominada Base de Operações Geólogo Pedro de Moura (Figura 1).

Figura 1. Localização da província petrolífera de Urucu (Coari), Google Earth, 2012.

Apresenta clima quente e úmido, com precipitações anuais em torno de $2.350 \mathrm{~mm}$, temperatura média anual de $27,8^{\circ} \mathrm{C}$, umidade relativa do ar indicando média anual de $82 \%$ (Vieira et al., 2005). Devido às suas características geológicas, apresenta solos superficiais com granulometria fina de baixa capacidade de suporte e carência de material pétreo superficial para construção civil. Tais materiais de textura fina são, em geral, sensíveis às variações de umidade, contribuindo para maior perda da sua capacidade de suporte devido à infiltração de água, sendo um problema em locais com altos índices pluviométricos - caso da região onde se localiza a base petrolífera da Petrobrás.

Devido a uma série de restrições ambientais (busca pela menor interferência possível ao meio ambiente, imposta à Petrobrás na execução de suas atividades), essa pesquisa mostra-se como uma alternativa técnico-ambiental, uma vez que reduz a exploração de recursos naturais e utiliza um estabilizante não poluente e não gerador de resíduos.

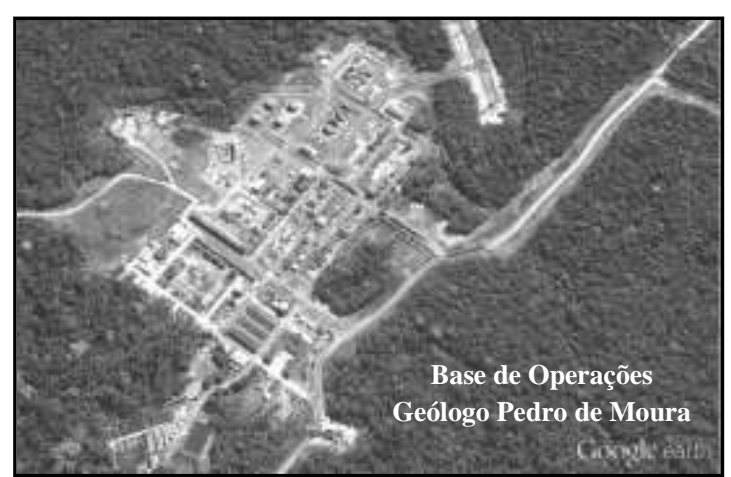

\section{OBJETIVO}

Estudar o comportamento mecânico de um solo típico da Base Petrolífera da Petrobrás, quando adicionado à emulsão asfáltica do tipo RL-1C. O trabalho tem como objetivos específicos: a) caracterizar geotecnicamente $\mathrm{o}$ solo natural; $\mathrm{b}$ ) analisar o comportamento mecânico do solo natural e das misturas solo-emulsão de acordo com a Resistência à Compressão Simples (RCS) e ensaios triaxiais de cargas repetidas (MR), variando os teores da emulsão, tempo de cura e aeração.

\section{MATERIAIS E MÉTODOS}

\subsection{Solo Natural}

As amostras coletadas em sacos de 40kg na estrada SUC (Sul de Urucu), foram transportadas até Manaus por via fluvial (Figura 2). Em laboratório, o material foi seco ao ar livre, destorroado e peneirado. Na sequência, realizarem-se os ensaios: limite de liquidez (NBR 6459/84), granulometria (NBR 7181/84), massa específica dos sólidos (NBR 6508/84) e mecânicos (RCS e MR). 

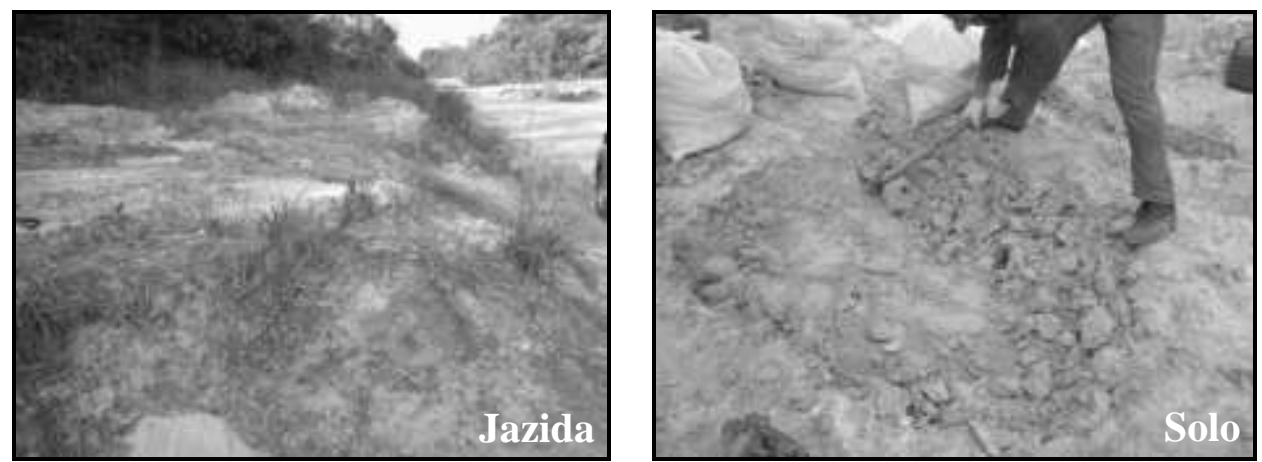

Figura 2. Jazida de Urucu.

No que se refere à análise granulométrica, com e sem defloculante, verificou-se o teor de agregação e o grau de alteração (relação silte/argila). Segundo Costa (1973, apud Pessoa, 2004), esta relação mostra-se como bom indicativo do grau de intemperismo dos materiais - grau de alteração maior ou igual a 15 define solos pouco evoluídos, enquanto que valores menores que 15 caracterizam solos antigos e intemperizados. A Tabela 1 mostra a forma de cálculo dos citados parâmetros.

Tabela 1. Cálculo do teor de agregados e grau de alteração

\begin{tabular}{c} 
Agregados Totais (\%) $=\%$ argila com defloculante $-\%$ argila sem defloculante \\
\hline Teor de Agregados (\%) $=100 x[$ Agregados totais $(\%) / \%$ argila com defloculante $]$ \\
\hline
\end{tabular}

Grau de Alteração $=\%$ silte $/ \%$ argila

\subsection{Emulsão Asfáltica}

O estabilizante é uma emulsão asfáltica catiônica de ruptura lenta (RL1C), adquirida na empresa Emulsões e Transportes Ltda (EMAM). Durante a realização dos ensaios foi armazenada em recipientes fechados.

\subsection{Ensaios Mecânicos}

Nos experimentos, incluindo $\mathrm{o}$ solo natural, submeteram-se os corposde-prova a duas condições de aeração 0 hora ("sem aeração") e 1 hora ("com aeração"). Moldaram-se, no mínimo, oito corpos-de-prova para o solo natural e misturas solo-emulsão, estas variando segundo os teores de $1 \%, 2 \%, 5 \%$ e $8 \%$ da emulsão RL-1C; sendo quatro rompidos após a moldagem (imediato/zero dia) e quatro após um período de sete dias de cura expostos à temperatura ambiente.

Determinaram-se os parâmetros de compactação (NBR 7182/86), concernente a cada teor de emulsão. Realizaram-se os ensaios mecânicos de Resistência à Compressão Simples (NBR 12770/92) e Módulo de Resiliência (ASTM AASHTO T 307-99) na prensa pneumática UTM $14 \mathrm{kN}$ (Universal Test Machine/IPC Global), mostrada na Figura 3. 


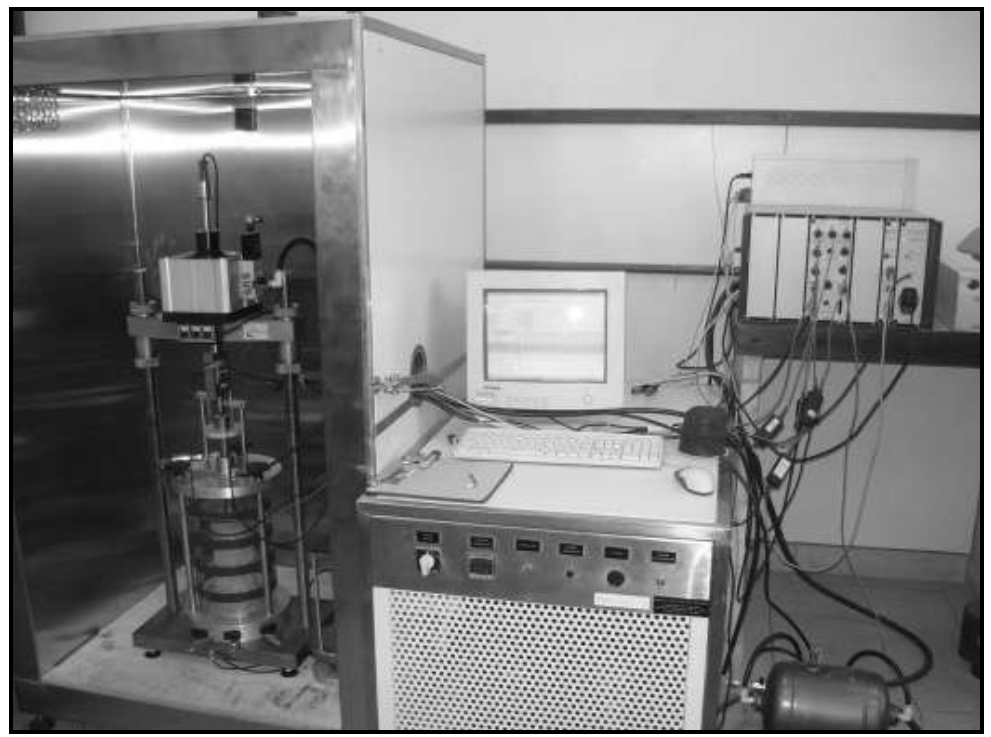

Figura 3. Maquina Universal de Ensaios (UTM).

Particularmente para o ensaio de RCS, confeccionaram-se os corpos de prova mantendo-se a relação 2:1, conforme é comumente empregado nesse tipo de experimento, com a altura sendo o dobro do diâmetro.

\section{RESULTADOS E DISCUSSÕES}

\subsection{Caracterização Geotécnica}

$\mathrm{Na}$ Figura 4 encontram-se os resultados da análise granulométrica com e sem defloculante, visando avaliar o teor de agregação. Com base nesses resultados, nota-se que o material mostra predominância de silte, sendo superior ao dobro da segunda fração (areia). Quanto à textura, o solo natural se classificou como silte areno-argiloso (com defloculante) e silte arenoso (sem defloculante). Portanto, nos dois casos tem-se a presença de uma matriz siltosa.

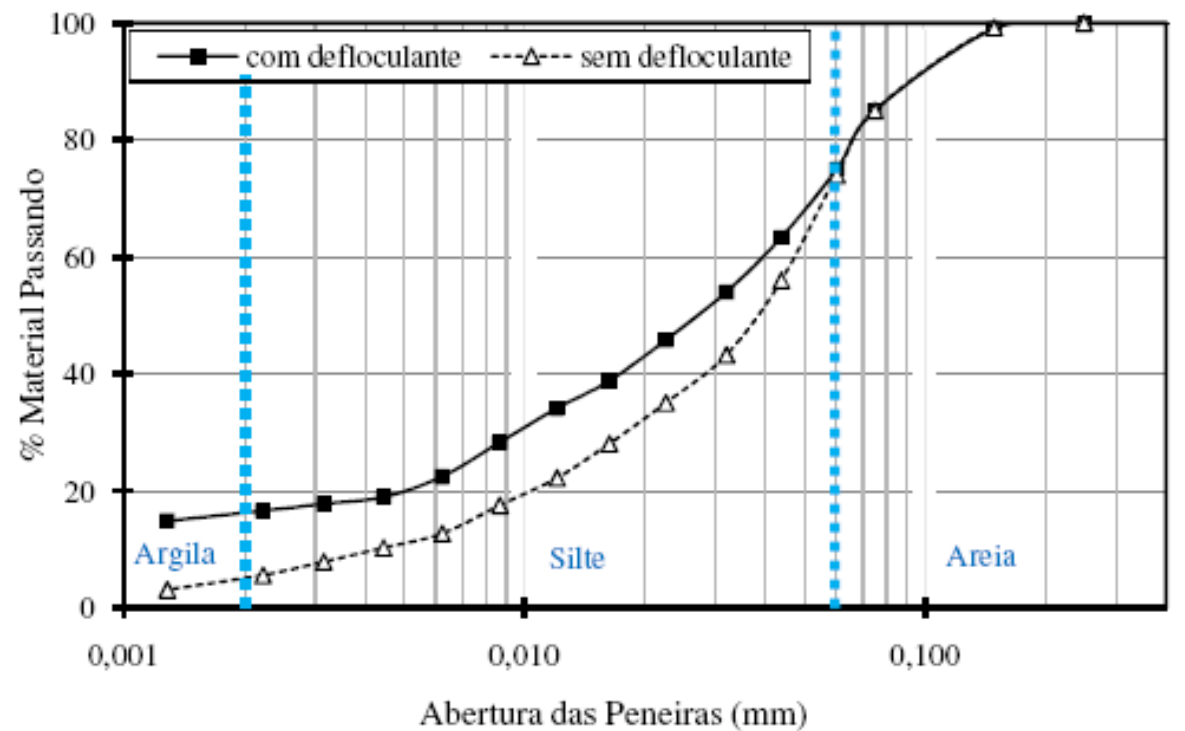

Figura 4. Curva granulométrica do solo. 
Tabela 2. Teor de agregados e grau de alteração

\begin{tabular}{c|c}
\hline Teor de Agregados (TA) & Grau de Alteração (GA) \\
\hline $71 \%$ & 3 \\
\hline
\end{tabular}

Verifica-se pela Figura 4 e Tabela 2, que: a) o teor de agregação apresentou um valor consideravelmente elevado, indicando que grande parte da fração argila encontra-se adicionada às partículas de silte. Esses resultados são coerentes com os valores encontrados por Pessoa (2004).

A Tabela 3 apresenta a classificação geotécnica - Transportation Research Board (TRB) e Sistema Unificado de Classificação de Solos
(SUCS), e os resultados do índice de plasticidade, granulometria e massa específica dos sólidos. Apesar das limitações a que estão sujeitas os dois sistemas de classificação para solos tropicais, os mesmos indicaram resultados coerentes quando confrontados com a granulometria e a plasticidade, ou seja, ambos os solos mostraram predominância siltosa e baixa plasticidade.

Tabela 3. Classificação geotécnica.

\begin{tabular}{c|c|c|c|c|c|c|c|c}
\hline $\mathbf{\rho}_{\mathbf{g}}$ & \multicolumn{2}{|c|}{ Índices } & \multicolumn{3}{c|}{ Porcentagem passante } & \multicolumn{2}{c}{ Classificação } \\
\cline { 2 - 8 }$\left(\mathbf{g} / \mathbf{c m}^{\mathbf{3}}\right)$ & LL (\%) & IP (\%) & $\# 4$ & $\# 10$ & $\# 40$ & $\# 200$ & TRB & SUCS \\
\hline 2,61 & 19 & 6 & 100 & 100 & 100 & 85 & A - 4 & ML \\
\hline
\end{tabular}

\subsection{Emulsão Asfáltica}

Ao ser adquirida a emulsão asfáltica catiônica de ruptura lenta (RL1C), a empresa forneceu as informações presentes na Tabela 4, na qual se observa que o resíduo da destilação (quantidade de água presente na emulsão) possui um valor igual a $39,84 \%$ em peso. Tal parâmetro mostra-se de suma importância no cálculo da dosagem solo-emulsão.

Tabela 4. Caracterização da emulsão RL-1C.

\begin{tabular}{l|c}
\hline Ensaio & Resultado \\
\hline Viscosidade Saybolt-Furol a $50{ }^{\circ} \mathrm{C}$ & 16,22 \\
\hline Peneiração, \% em peso & 0,0 \\
\hline Carga da partícula & positiva \\
\hline Resíduo da destilação, \% em peso & 60,16 \\
\hline
\end{tabular}

\subsection{Compactação}

A Figura 5 apresenta o comportamento das curvas de compactação, onde se constatou que: a) a adição de teores de emulsão não alterou significativamente os valores do peso especifico aparente seco máximo e da umidade ótima e b) o tempo de aeração não influenciou nos parâmetros de compactação do solo natural, porém, ocorreram discretas modificações nas misturas solo-emulsão. 


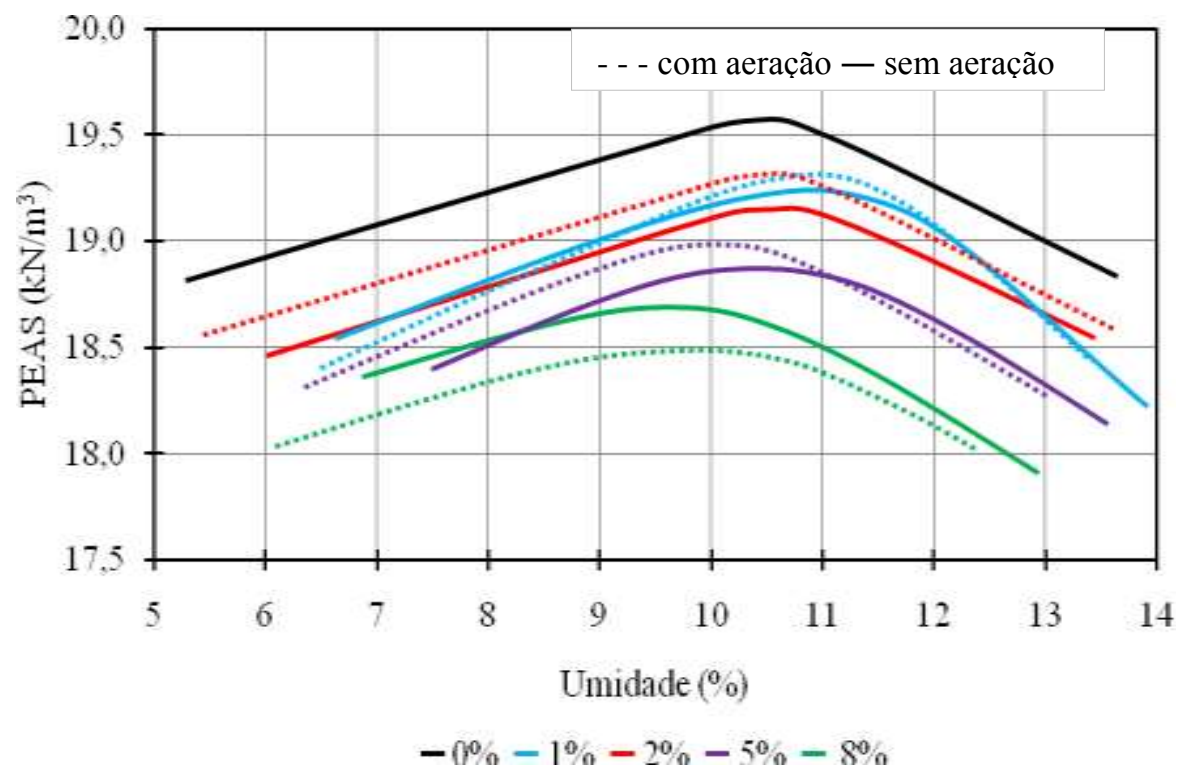

Figura 5. Curva de Compactação - solo natural e misturas com e sem aeração.

Tratando-se especificamente dos parâmetros de compactação, concluiu-se que: a) os pesos específicos das misturas solo-emulsão indicaram valores semelhantes, tendo o aumento dos teores do material asfáltico ocasionado reduções dos PEAS; e b) a umidade ótima, em geral, apresentou discreta redução com o aumento dos teores de emulsão e nas misturas solo-emulsão mostraram-se superiores alusivas ao solo natural.

\subsection{Comportamento Mecânico}

Nas Figuras 6 e 7 têm-se as deformações referentes ao ensaio de compressão não confinada (RCS), para as amostras com e sem aeração. Notou-se, que: a) os corpos-de-prova ensaiados para zero dias mostraram, em sua maioria, as maiores deformações; b) o acréscimo dos teores da emulsão, em geral, diminuíram as deformações; e c) as deformações das amostras com aeração foram relativamente inferiores quando comparadas aos corpos de prova sem aeração.

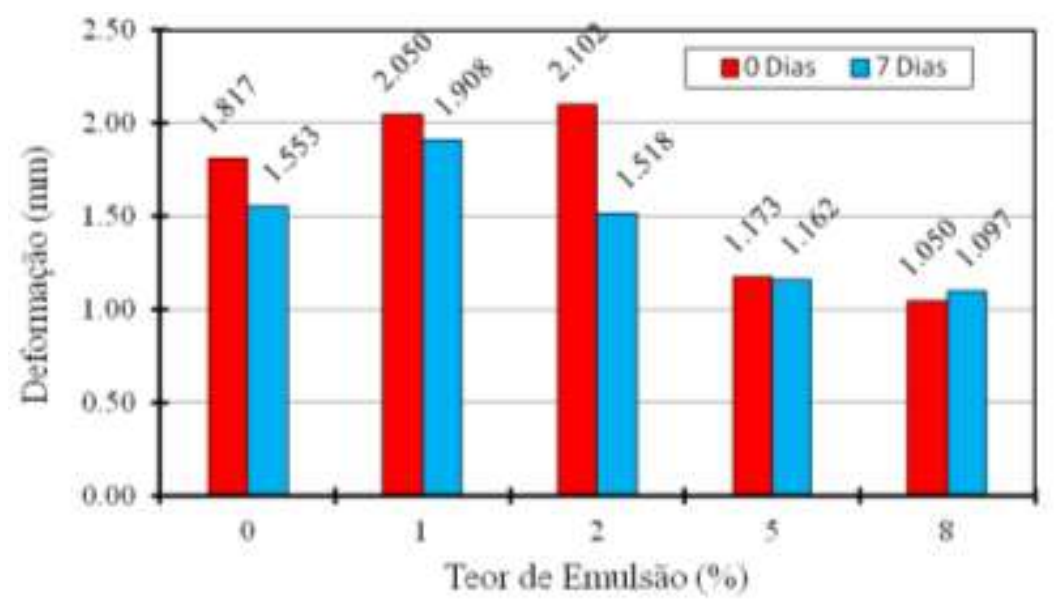

Figura 6. Deformação dos corpos-de-prova com aeração. 


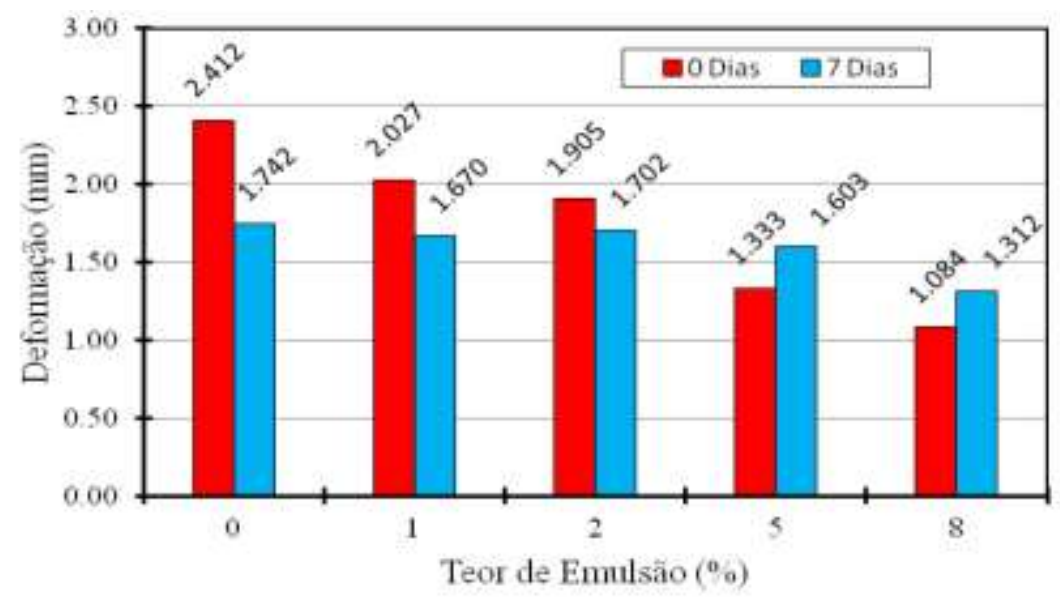

Figura 7. Deformação dos corpos-de-prova sem aeração.

Na Figura 8 apresenta-se o efeito da emulsão na contribuição do ganho em resistência, após um período de sete dias, por meio da avaliação individual de cada teor, fixando-se os resultados nos ensaios imediatos (0 dias) como 100\%. Desta forma, observou-se a importante contribuição da emulsão asfáltica no comportamento mecânico das misturas, dado pela RCS.

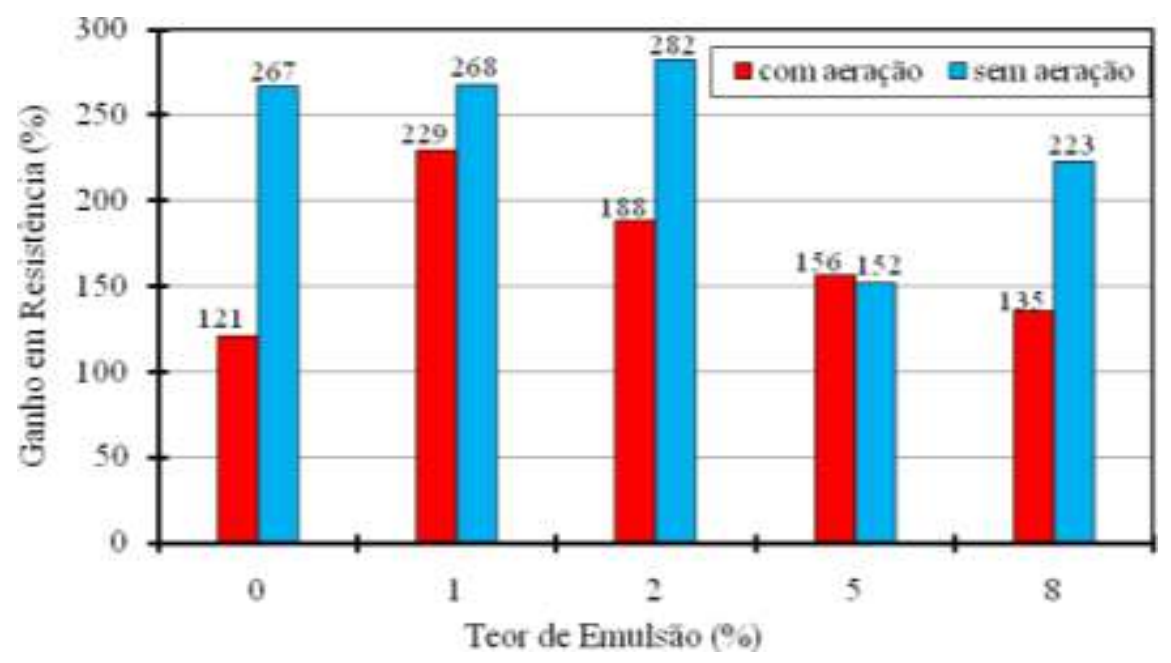

Figura 8. Ganho em resistência pelo efeito da cura após sete dias.

Segundo ainda a Figura 8 verificou-se que: a) os corpos-de-prova obtiveram um ganho de resistência acima de $100 \%$, decorrente também da perda de umidade do material; b) o solo natural sem aeração apresentou um aumento de resistência em torno do dobro relativo às condições com aeração. No entanto, este ganho é menos acentuado para as misturas solo-emulsão; c) nas amostras com aeração, à medida que se reduziu o teor de emulsão, ocorreram resultados de acordo com o período de cura. Contudo, ressalta-se que estes valores se mostraram superiores ao solo natural, em termos de resistência absoluta apenas para o teor $1 \%$; d) nas amostras sem aeração os teores de emulsão não ocasionaram resistência superior referente ao solo natural; e) tratando-se do tempo de aeração, observou-se que o ganho de resistência foi ocasionado não só pela ruptura, mas igualmente pela perda de umidade. 


\subsection{Triaxial de Cargas Repetidas}

Na Tabela 6 têm-se os parâmetros atinentes ao modelo composto para as amostras com e sem aeração. Os programas LabFit e MATLAB foram empregados no tratamento dos dados e posterior compilação dos gráficos.

Tabela 6. Parâmetros do modelo composto - com e sem aeração.

\begin{tabular}{|c|c|c|c|c|c|c|c|c|c|}
\hline \multicolumn{10}{|c|}{ Modelo Composto $\left(M R=k_{1} \sigma_{3}{ }^{k 2} \sigma_{d d}{ }^{k 3}\right)$} \\
\hline \multicolumn{2}{|c|}{ Corpos-de-prova } & \multicolumn{4}{|c|}{ Com Aeração } & \multicolumn{4}{|c|}{ Sem Aeração } \\
\hline $\begin{array}{c}\text { Teor de } \\
\text { Emulsão }\end{array}$ & $\begin{array}{c}\text { Cura } \\
\text { (dias) }\end{array}$ & $\mathrm{k}_{1}$ & $\mathrm{k}_{2}$ & $\mathrm{k}_{3}$ & $\mathrm{R}^{2}$ & $\mathrm{k}_{1}$ & $\mathrm{k}_{2}$ & $\mathrm{k}_{3}$ & $\mathrm{R}^{2}$ \\
\hline \multirow{2}{*}{$0 \%$} & 0 & 512,6 & 0,1988 & $-0,0253$ & 0,937 & 419,2 & 0,3754 & $-0,0657$ & 0,951 \\
\hline & 7 & 1305 & 0,1263 & 0,1170 & 0,936 & 1133 & 0,1530 & 0,1553 & 0,975 \\
\hline \multirow{2}{*}{$1 \%$} & 0 & 421,0 & 0,2646 & 0,0228 & 0,987 & 424,7 & 0,3641 & $-0,0372$ & 0,982 \\
\hline & 7 & 1514 & 0,2020 & 0,2567 & 0,981 & 1102 & 0,2013 & 0,0974 & 0,962 \\
\hline \multirow{2}{*}{$2 \%$} & 0 & 368,5 & 0,2813 & $-0,1152$ & 0,947 & 404,4 & 0,3624 & $-0,0986$ & 0,952 \\
\hline & 7 & 1259 & 0,1848 & 0,1096 & 0,987 & 1141 & 0,1543 & 0,1482 & 0,957 \\
\hline \multirow{2}{*}{$5 \%$} & 0 & 313,1 & 0,2082 & $-0,1181$ & 0,949 & 465,0 & 0,2196 & 0,0805 & 0,987 \\
\hline & 7 & 1076 & 0,1099 & 0,1138 & 0,957 & 1043 & 0,2233 & 0,1834 & 0,975 \\
\hline \multirow{2}{*}{$8 \%$} & 0 & 334,0 & 0,1889 & $-0,1279$ & 0,954 & 423,9 & 0,3617 & $-0,0322$ & 0,939 \\
\hline & 7 & 1033 & 0,1171 & 0,1264 & 0,930 & 1086 & 0,1408 & 0,2324 & 0,948 \\
\hline
\end{tabular}

Verificou-se, pelos coeficientes de correlação $\left(\mathrm{R}^{2}\right)$, para os tempos de aeração (zero e 1 hora) e todas as situações estudadas, um desempenho satisfatório do modelo composto (Tabela $6)$.

A Figura 9 apresenta os gráficos em que são agrupadas as superfícies referentes ao solo natural e as misturas para diferentes teores de emulsão, referentes ao ensaio com aeração. É possível visualizar que, apesar da ocorrência de acréscimos de MR com o aumento dos teores de emulsão, o solo natural apresentou valores superiores. Ressalta-se que as amostras, com e sem material asfáltico, mostraram uma maior dependência para baixas tensões desvio.
Com relação à adição de emulsão, exemplificada nas Figuras 9a e 9b, os gráficos indicam que o material asfáltico promoveu uma redução nos valores do módulo de resiliência, e que a zero dia de cura e para os teores de $5 \%$ e $8 \%$ de emulsão resultaram valores de MR superiores aos outros teores.

Com o objetivo de facilitar a visualização do comportamento resiliente, introduziu-se a Figura 9c. Verificam-se, após sete dias, oscilações nos valores de MR. Por exemplo, para a amostra com $1 \%$ de emulsão tais valores foram susceptíveis a baixas tensões desvio. 


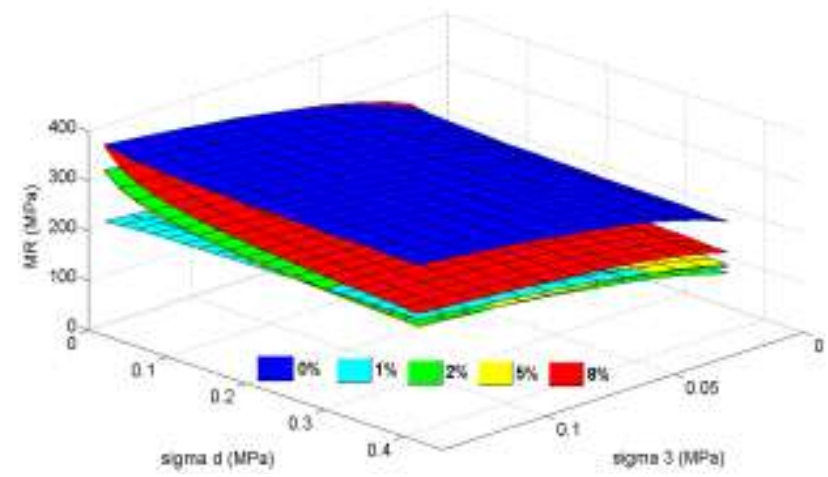

a) Cura de 0 dias

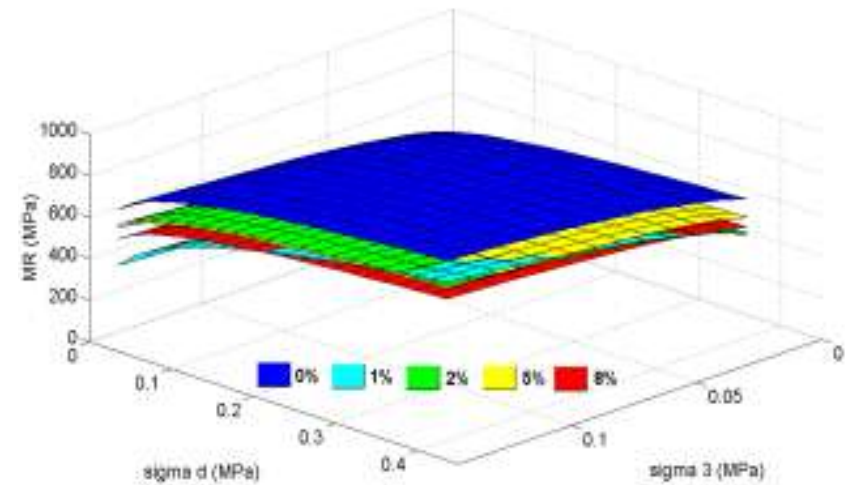

b) Cura de 7 dias

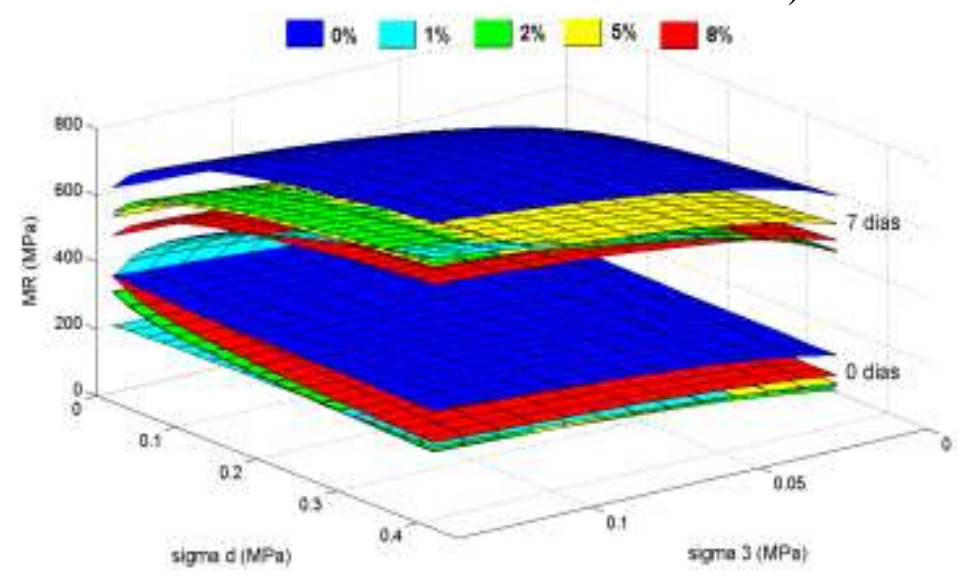

c) 0 dias $x 7$ dias

Figura 9. Módulos de Resiliência para as misturas com aeração.

A Figura 10 reúne o comportamento das amostras sem aeração, ensaiadas de imediato. Desta vez, são observadas melhorias nos comportamentos resilientes das misturas solo-emulsão, particularmente nos teores de $2 \%$ e $5 \%$, onde se constatou uma ligeira superioridade alusiva ao solo natural.

Pelos resultados constantes na Figura 10a, tem-se que o ensaio após a compactação (imediato) resultou módulos de resiliência mais altos, quando da adição de emulsão em $2 \%$ e $5 \%$, referentes ao solo natural. Atenção especial é dada ao teor de $5 \%$, onde se observa uma mudança expressiva no comportamento da superfície, mostrandose uma condição com melhores respostas resilientes.

Na Figura 10b têm-se as amostras ensaiadas após sete dias. Observa-se que a adição de $2 \%$ promoveu um ligeiro aumento nos valores de MR após o referido período, se comparados aos valores do solo natural. Este melhor comportamento resiliente após a cura de sete dias, se deve a perda de umidade, aliado à influência do mencionado teor de emulsão. Nota-se, ainda, que as superfícies atinentes ao solo natural e às misturas com $1 \%$ e $2 \%$ de RL-1C, apresentaram-se praticamente superpostas, indicando que o tempo da adição da emulsão não exerceu influência sobre o MR.

Em resumo aos resultados de MR para o solo natural e misturas soloemulsão, verificou-se, por meio da Figura $10 \mathrm{c}$, que as amostras sem aeração, com $2 \%$ de emulsão asfáltica e cura de sete dias, mostraram-se com melhor desempenho. 


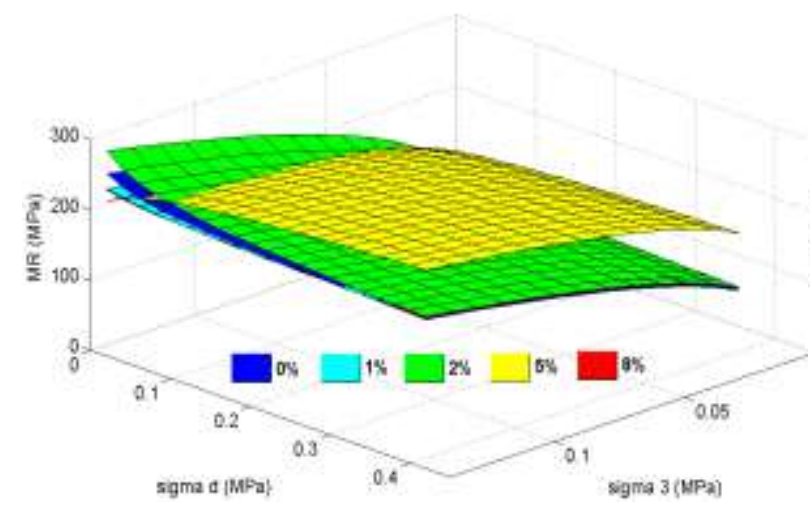

a) Cura de 0 dias

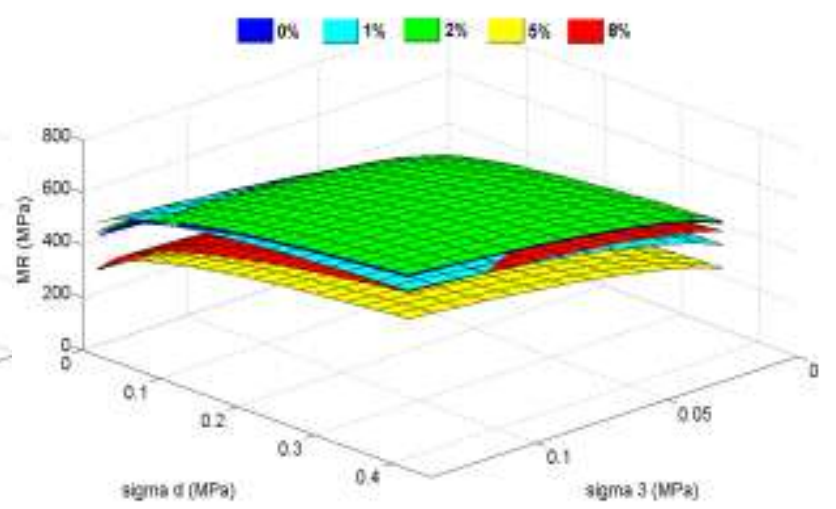

b) Cura de 7 dias

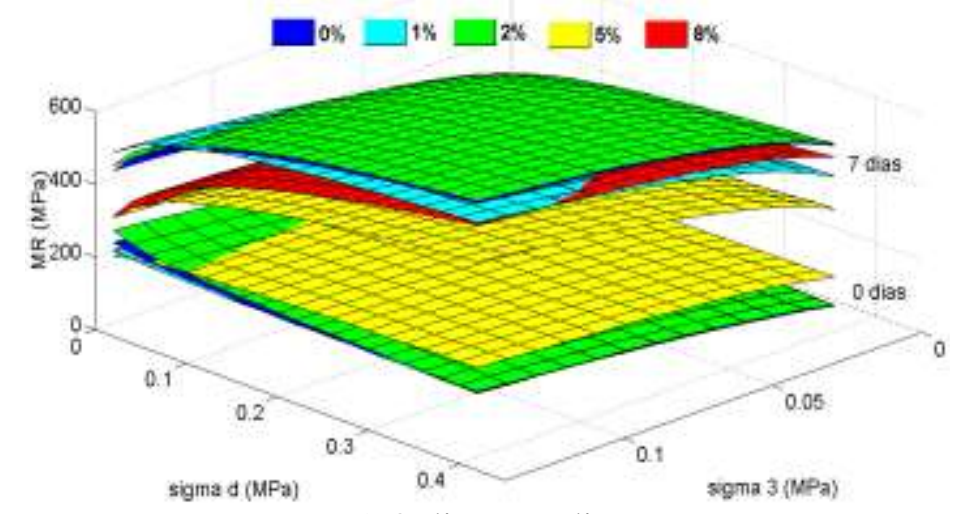

c) 0 dias $x 7$ dias

Figura 10. Módulos de Resiliência para as misturas sem aeração.

Estudos semelhantes realizados por Miceli (2006), Soliz (2007) e Gondim (2008), com o mesmo tipo de emulsão, indicaram adequabilidade do ensaio de módulo de resiliência, quando analisada a influência do material asfáltico no desempenho mecânico dessas misturas. Segundo tais autores, observaram-se melhorias significativas para o período de cura de sete dias.

\section{CONCLUSÕES}

\subsection{Ensaios de Caracterização}

a) A adição da emulsão ao solo natural não alterou significativamente a umidade ótima de compactação;

b) $\mathrm{O}$ acréscimo percentual da RL-1C não apresentou mudanças significativas nos valores $\gamma_{\text {dmáx }}$ e $w_{\text {ót }}$;

c) O tempo de uma hora de aeração suscitou discretas alterações nos parâmetros de compactação das misturas.

\subsection{Ensaios de Resistência à Compressão Simples (RCS)}

a) $\mathrm{O}$ solo natural e as misturas soloemulsão, com aeração, ensaiados de imediato, mostraram-se, em geral, superiores às amostras sem aeração. $\mathrm{O}$ comportamento inverteu-se após o período de 7 dias de cura;

b) Com relação ao ganho de resistência após sete dias de cura, a mistura soloemulsão apresentou uma ligeira superioridade ao solo natural para o teor de $1 \%$, nas condições de aeração;

d) As misturas solo-emulsão indicaram menores deformações, sendo, de forma geral, tanto menor quanto maior a porcentagem de emulsão. 


\subsection{Ensaios Triaxiais de Cargas Repetidas}

a) A aeração ocasionou modificações nos valores do MR para as amostras com e sem emulsão;

b) Os ensaios do MR, respeitantes aos experimentos de RCS, apresentaram-se os mais adequados para análise da influência da adição da emulsão asfáltica nos solos regionais;

c) Os resultados do MR, independente do tempo de cura, para amostras com aeração, indicaram-se superiores àqueles sem aeração;

d) O percentual de $2 \%$ e cura de sete dias, sem aeração, resultou no melhor comportamento alusivo à resposta resiliente do solo de Urucu.

\section{REFERÊNCIAS}

ABNT NBR-6459 Solo - Determinação do Limite de Liquidez. Rio de Janeiro, 1984. $6 \mathrm{p}$.

ABNT NBR-6508 Grãos de Solo que Passam na Peneira de 4,8mm Determinação da Massa Específica. Rio de Janeiro, 1984. 8 p.

ABNT NBR-7181 Solo - Análise Granulométrica. Rio de Janeiro, 1984. 13 p.

ABNT NBR-7182 Solo - Ensaio de compactação. Rio de Janeiro, 1984. 10 p.

ABNT NBR-7180 Solo - Determinação do Limite de Plasticidade. Rio de Janeiro, 1984. 3 p.

ABNT NBR-12770 Solo coesivo Determinação da resistência à compressão não confinada: Rio de Janeiro, 1992. 4 p.

American Association of State and Highway Transportation Officials AASHTO, Standard Method of Test for Determining the Resilient Modulus of
Soils and Aggregate Material, T 307-99. 2003. p. 43.

FROTA, C. A., SILVA, C. L., NUNES, F. R. G. Estudo da Exploração de Argila para Fins de Calcinação, Visando a Construção de Pavimentos na Província Petrolífera de Urucu-AM-Brasil. In: V Jornadas Luso-Brasileiras de Pavimentos: Políticas e Tecnológicas. Trabalho V046. Recife, PE, 2006.

GODIM, L. M. Estudo do Experimental de Misturas Solo-Emulsão Aplicado às Rodovias do Agropólo do Baixo Jaguaribe/Estado do Ceará. 2008. 213 f. Dissertação de M. Sc., Programa de Mestrado em Engenharia e Transporte, Universidade Federal do Ceará, Fortaleza, CE.

MICELI, J. G. Comportamento de Solos do Estado do Rio de Janeiro Estabilizados com Emulsão Asfáltica. 2006. 256 f. Dissertação de M. Sc. Instituto Militar de Engenharia, IME, Rio de Janeiro.

PESSOA, F. H. C. Análises dos Solos de Urucu para Fins de Uso Rodoviário. 2004. 151 f. Dissertação de M. Sc., Departamento de Engenharia Civil e Ambiental, Universidade de Brasília, Brasília.

SOLIZ, V. V. P. Estudo de Três Solos Estabilizados com Emulsão Asfáltica. 2007. 166 f. Dissertação de M. Sc., COPPE/UFRJ, Universidade Federal do Rio de Janeiro, Rio de Janeiro.

VIEIRA, A. F. G., MOLINARI, D. C., ALBUQUERQUE, A. R. C., Dinâmica Erosiva em Estradas: BR-174 e Urucu (AMAZONAS). In: II Simpósio Sobre Solos Tropicais e Processos Erosivos no Centro-Oeste. Goiás, 2005. 